\title{
Mulemba
}

Revista Angolana de Ciências Sociais

\section{As metodologias da animação e mediação sociocultural na reeducação e reintegração social de menores}

The methodologies of animation and socio-cultural mediation in the rehabilitation and social reintegration of minors

Teodora Leite

\section{OpenEdition}

Journals

Edição electrónica

URL: http://journals.openedition.org/mulemba/390

DOI: $10.4000 /$ mulemba.390

ISSN: 2520-0305

Editora

Edições Pedago

Edição impressa

Data de publição: 1 maio 2015

Paginação: 161-184

ISSN: 2182-6471

Refêrencia eletrónica

Teodora Leite, «As metodologias da animação e mediação sociocultural na reeducação e reintegração social de menores», Mulemba [Online], 5 (9) | 2015, posto online no dia 28 novembro 2016, consultado o 26 janeiro 2021. URL: http://journals.openedition.org/mulemba/390 ; DOI: https://doi.org/10.4000/ mulemba.390

Este documento foi criado de forma automática no dia 26 janeiro 2021.

Tous droits réservés 


\title{
As metodologias da animação e mediação sociocultural na reeducação e reintegração social de menores
}

\author{
The methodologies of animation and socio-cultural mediation in the \\ rehabilitation and social reintegration of minors
}

Teodora Leite

\section{NOTA DO EDITOR}

Recepção do manuscrito: 02/01/2015

Conclusão da revisão: 05/04/2015

Aceite para publicação: 20/04/2015

\section{Introdução}

A presente pesquisa visa fazer uma abordagem sobre a utilização e eficácia de estratégias e metodologias da animação e da mediação sociocultural nomeadamente, a dramatização, as dinâmicas de grupo, os métodos audiovisuais e os métodos não interferentes na reeducação e reintegração social de menores. A referida abordagem tem como contexto de estudo o Centro de Formação Integral Kalakala. Esta instituição situa-se em Luanda e está vocacionada a reeducação de adolescentes e jovens que vivem em situação de risco, provenientes sobretudo das ruas, facto que os torna indivíduos vulneráveis à delinquência. Deste modo, pode-se dizer que os menores que frequentam a instituição são considerados indivíduos com comportamentos desviados, isto é, não obedecem aos padrões normais de conduta social. Assim, pretendemos perceber a 
influência do Centro nas mudanças morais e comportamentais dos indivíduos implicados.

2 A razão da escolha do tema prende-se com o facto de ser um assunto de grande interesse para a sociedade angolana, uma vez que são inúmeros os problemas vividos por esse extracto da população. Estes fenómenos, de ordem familiar, económica e social, que se vivem com maior incidência na população adolescente e jovem em Angola, promovem situações como a existência de meninos de rua e a delinquência infanto-juvenil. Posto isto, afigura-se-nos fundamental que sejam encontradas medidas de reeducação e de reinserção social desses menores através de actividades programadas para o efeito. Neste sentido, o recurso às metodologias da animação e da mediação sociocultural parece-nos ser favorável para a situação em causa.

3 Tendo em atenção que procuramos compreender todo o processo inerente à reeducação e reinserção social dos menores internados no centro de formação, as interrogações que orientaram esta investigação são:

a. A aplicação de estratégias, metodologias e técnicas inerentes à animação e à mediação sociocultural é eficaz para a reeducação e reintegração social de menores que vivem em situação de risco?

b. Que representação têm as diversas actividades nas quais foram utilizadas as estratégias, metodologias e técnicas da animação e da mediação sociocultural para os menores envolvidos no processo de reeducação e reintegração social?

Desta forma, os nossos objectivos passam por apresentar a utilização e eficácia das metodologias da animação e mediação sociocultural no programa de reinserção social de menores em risco do Centro de Formação Integral Kalakala. Para o efeito, procuramos perceber as linhas de homogeneidade e de diversidade dentro da população juvenil do Centro de Formação Kalakala; compreender quais os elos de ligação existentes entre os menores, os educadores, as famílias dos menores e a comunidade circunvizinha do centro; analisar o significado que os indivíduos atribuem às actividades realizadas no Centro Kalakala, nas quais, eventualmente, são utilizadas as estratégias, metodologias e técnicas da animação e da mediação sociocultural; disseminar para a sociedade em geral, o valor social da reeducação e reinserção destes indivíduos, tendo em conta as suas dimensões pessoais e sociais.

5 Relativamente a metodologia utilizada e de acordo com o nosso objectivo optamos pela pesquisa qualitativa, uma vez que esta tem um carácter interpretativo e descritivo. Para este efeito, recorremos às técnicas de entrevista semidirectas com questões abertas aplicadas em dois momentos. Primeiramente, aplicadas aos adolescentes e jovens da instituição e posteriormente aplicadas aos funcionários da mesma. A análise documental foi de igual modo utilizada. Esta técnica foi empregada a partir de fontes oficiais em Angola e de alguma pesquisa bibliográfica. Utilizamos ainda como técnica qualitativa a observação directa dada a autenticidade, a naturalidade e a actualidade que a mesma possui. A fusão dessas técnicas permitiu-nos captar de forma mais abrangente as informações necessárias para a pesquisa.

Quanto aos resultados obtidos com essa investigação, pensamos que os mesmos podem servir de trampolim para reflexão e solução de problemas vividos na actualidade dentro da sociedade angolana, tendo em conta que se verificou que a utilização de estratégias e metodologias da animação e da mediação sociocultural mostra-se eficaz para a reeducação e reintegração social de adolescentes e jovens em situação de risco. Com essa investigação, procuramos ainda elucidar a sociedade sobre as diferentes aplicações 
possíveis de técnicas para a reeducação e reintegração social de menores e incentivar o seu uso em instituições angolanas apropriadas para o efeito.

\section{Métodos e técnicas de investigação}

7 Tal como já aludimos, optamos pela metodologia qualitativa, tendo em conta os objectivos da pesquisa e o tipo de população alvo a ser estudado, uma vez que, esta abordagem possui um carácter interpretativo e descritivo e as suas técnicas permitem conceber hipóteses de investigação favoráveis (SOUSA e BAPTISTA 2011).

8 Nesta perspectiva, o nosso método de estudo é um estudo de caso feito no Centro de Formação Integral Kalakala. Segundo Yin, o estudo de caso «é uma investigação empírica que investiga um fenómeno contemporâneo dentro de seu contexto da vida real, especialmente quando os limites entre o fenómeno e o contexto não estão claramente definidos» (OLIVEIRA e GALEGO 2005: 69). Assim sendo, a escolha pela utilização deste instrumento metodológico foi, portanto, com a intenção de trabalhar num problema real da sociedade angolana, tentando compreender e explicar o processo de reabilitação e reinserção social dos adolescentes e jovens da instituição.

Uma vez que a pesquisa qualitativa é uma metodologia composta por diversas técnicas, recorremos, então, a fusão de técnicas de investigação social adequadas a mesma, designadamente: a aplicação de entrevistas, a observação directa e a análise documental, esta última utilizada, sobretudo, para o enquadramento teórico da investigação. A opção pelo recurso a estas diferentes técnicas de recolha de dados devese ao facto de podermos complementá-las. Assim sendo, situações não captadas por uma técnica possivelmente puderam ser captadas por outra técnica.

\section{A aplicação de entrevistas}

10 As entrevistas foram realizadas no Centro Kalakala num período de cerca de três semanas ao longo dos meses de Julho e Setembro de 2012. Foram assim entrevistados trinta e cinco indivíduos e efectuadas cerca de 175 horas de entrevista aos rapazes internados com idades compreendidas entre os 14 e os 18 anos. Numa abordagem mais centrada no processo de reeducação e reabilitação dos internados, foram entrevistados sete indivíduos e efectuadas cerca de 210 horas de entrevistas aos profissionais do centro.

11 Segundo Pierre Bourdieu, «a entrevista pode ser considerada como uma forma de exercício espiritual, visando a obter, pelo esquecimento de si, uma verdadeira conversão do olhar que lançamos sobre os outros nas circunstâncias comuns da vida» (BOURDIEU 2003: 704). Assim, o carácter flexível desta técnica permite maior aproximação entre o entrevistador e o entrevistado (QUIVY e CAMPENHOUDT 1992). É, no entanto, em função do público-alvo desta investigação (adolescentes e jovens em situação de risco) que pensamos que uma aproximação entre os dois interlocutores mostra-se como uma mais-valia, para o bom funcionamento da pesquisa. De acordo com os guiões elaborados, realizamos entrevistas semidirectas com questões abertas que nos deram a possibilidade de recolha de informações mais detalhadas.

12 Nesse sentido, as entrevistas foram aplicadas em duas etapas. Numa primeira fase, foram entrevistados os menores que vivem na instituição. Porquanto, estas entrevistas 
tiveram como objectivos compreendermos a trajectória de vida dos menores até a chegada na instituição, as actividades quotidianas dos mesmos dentro da instituição e, também, compreender até que ponto são, ou não, alcançadas as expectativas por eles traçadas. Foram, igualmente, entrevistados os técnicos e a direcção geral da instituição numa fase posterior. Desse modo, com esta segunda etapa de entrevistas, percebemos como ocorre o processo de reeducação e reintegração social dos menores, o processo de mediação de conflitos, e em que medida são, ou não, utilizadas as estratégias e as metodologias da animação e da mediação sociocultural na instituição.

\section{A observação directa}

ste método tem como vantagem a captura real e directa de dados importantes como o comportamento dos indivíduos, a captura natural de dados não previstos pelo investigador e, ainda, a validade dos casos (QUIVY e CAMPENHOUDT 2003). Deste modo, a observação directa (apoiada nas notas de campo) foi efectuada no período de recolha de dados na instituição, visto que esta permite que durante o processo de observação se possam anotar as situações inabituais (CRESWELL 2007). Na mesma perspectiva, esta técnica é útil para investigações nas quais os pesquisadores procuram melhor perceber uma realidade social por estes desconhecida, facilitando assim a sua adaptação a esta mesma realidade social (LESSARD-HÉBERT et al., 1994).

Assim sendo, a autenticidade, a naturalidade e a actualidade são catalisadores para que este instrumento permita a recolha de informação por vezes não mencionada durante a fase das entrevistas por esquecimento, desconhecimento ou omissão voluntária de certas situações. Nesse sentido e de acordo com os nossos objectivos, a breve estadia que efectuamos na instituição permitiu, por meio da observação directa, ter uma visão mais abrangente sobre os comportamentos dos entrevistados afora das entrevistas.

Dessa forma, fizemos uma observação do tipo exploratória acompanhada de conversas informais o que nos possibilitou, de maneira mais confortável, verificar o comportamento e as tarefas quotidianas dos menores e dos funcionários do centro Kalakala. Contudo, a nossa curta estadia na instituição, não nos permitiu conhecer de maneira profunda as diferenças comportamentais dos indivíduos, os tipos de comunidades e de sociabilidades dentro da instituição, as estratégias do exercício de autoridade, assim como os indivíduos e/ou grupos de trabalho de referência.

\section{A análise documental}

16 A técnica de análise documental, permite a legitimação das informações recolhidas. Assim sendo, a mesma foi feita a partir de fontes oficiais em Angola sem, no entanto, termos deixado de fazer o recurso à pesquisa bibliográfica como instrumento de suporte teórico. Nesse sentido, foram fundamentais os dados obtidos, entre outros, através de documentos da instituição (Kalakala), os documentos do Programa das Nações Unidas para o Desenvolvimento (PNUD) e, de igual modo, os dados do Instituto Nacional de Estatística (INE) de Angola que nos permitiram ter uma visão da situação angolana. 


\section{Resultados: As metodologias da animação e da mediação sociocultural}

17 A animação cultural pode ser compreendida como uma fusão de práticas sociais e humanas utilizadas para o desenvolvimento harmonioso e participativo de uma determinada comunidade. Esta é, portanto, um agente de intervenção e de transformação da sociedade. Nesse sentido, figuram duas vertentes características, designadamente, por um lado, a vertente didáctica-pedagógica, que procura adequar as actividades a serem aplicadas em função do currículo escolar dos indivíduos inseridos no processo de ensino e aprendizagem; e, por outro lado, a vertente lúdica, que se adequa às actividades recreativas do mesmo processo. Na sua origem, permite o tratamento da cultura no seu ambiente natural uma vez que envolve diversidade, camaradagem e criatividade. Deste modo, «o objectivo central da animação sociocultural é estimular nos indivíduos e na comunidade uma atitude aberta e decidida para se incorporarem nas dinâmicas e nos processos sociais e culturais que os afectam e também para se responsabilizarem na medida que lhes corresponder» (TRILLA 2004: 29).

18 À semelhança do que ocorreu em Portugal na década de 1990, na qual viveu-se uma época de pouco investimento na profissionalização da animação sociocultural, infelizmente esta ideia exprime aquilo que ainda se vive actualmente em Angola. No entanto, apesar das mudanças que ocorrem actualmente nas políticas públicas de cultura em Angola, as actividades ligadas a área da animação sociocultural carecem, ainda, de maior atenção por parte do poder local. Desse modo, em termos de profissionalização, notamos o défice ao nível da existência de cursos para animadores porquanto, se vive com base nas experiências de vida de pessoas que se dedicam a esta prática, e/ou ainda com a proliferação e colaboração de movimentos associativos. Este facto leva-nos a corroborar com a ideia de Maria de Lourdes Santos, segundo a qual, «o movimento associativo constitui, provavelmente, o domínio de maior aplicação das metodologias de animação cultural, enquanto "laboratório" permanente da acção colectiva organizada» (SANTOS 1998: 255-256).

19 Nesta vertente, não se pode deixar de referir, igualmente, uma situação que não é estranha, o facto de não haver em Angola uma entidade que regule a formação de animadores culturais. Atendendo a diversidade cultural, etnolinguística e religiosa existente no país é de lamentar a não profissionalização de animadores culturais já que esses profissionais muito poderiam contribuir para solucionar diversos problemas de âmbito sociocultural.

20 A utilização das estratégias e metodologias da animação sociocultural nos adolescentes e jovens em situação de risco deve ter em conta as características deste grupo alvo, destacando elementos como: a idade, a cultura, os princípios, a sede de globalização e as novas experiências e, além disso, as suas trajectórias de vida. Para que tal aconteça com alguma eficácia, podem ser propostas actividades fundamentadas a partir de: «sessões especializadas (saúde, higiene, expressão corporal-musical-plástica), apoio escolar, jogos, excursões, dinâmicas de grupo, fóruns de vídeo, colónias de férias e acampamentos, ludotecas, desporto [...]» (GARCÍA 2004: 277).

21 Contudo, a animação sociocultural está interligada com a mediação cultural e é de salientar que algumas vezes são confundidas as funções de um animador cultural com as funções de um mediador cultural. Entretanto, existem funções inerentes a estes dois 
tipos de profissionais, tais como: o incremento de acções lúdicas; a interacção desses profissionais com outros profissionais da mesma área; a assistência a camada jovem; o vínculo entre indivíduo e comunidade; a mediação de conflitos (OLIVEIRA e GALEGO 2005).

Para José Vasconcelos-Sousa, «a mediação é uma forma privada e não-conflitual de prevenção $e$ de resolução de diferendos entre pessoas, empresas e organizações. 0 que a distingue de outros meios é o facto de o poder de decisão se manter nas mãos das partes em conflito (os mediados)» (VASCONCELOS-SOUSA 2011: 82). Outrossim, a mediação enaltece objectivamente os conflitos e impulsiona as partes a cooperarem no tratamento das situações problemáticas (OLIVEIRA e GALEGO 2005).

O processo de mediação varia consoante as circunstâncias e a região onde é aplicado. Nesta senda, evidenciamos que a prática da mediação sociocultural não é um processo muito frequente em Angola. Tal como acontece com a animação sociocultural, também se nota um grande défice na área da mediação sociocultural, pois ao nível da profissionalização não há no país uma formação específica para mediadores. Existem, porém, algumas formações como é o caso da formação em direito, sociologia e serviço social, que possuem nos seus conteúdos didácticos matérias ligadas a mediação. Como consequência disso, não existe em Angola um órgão que ajuste as diferentes práticas de mediação no país. Seguindo este prisma, é conveniente dizer que apesar do défice apresentado, a mediação em Angola pode ser utilizada em diversas áreas de interesse e actuação. Contudo, considera-se que a falta de profissionais que se faz sentir nesta área resulta em um verdadeiro abismo para o desenvolvimento da profissão de mediador.

Sendo um dos objectivos da presente investigação, compreender quais os elos existentes entre os menores, os educadores, as famílias dos menores e a comunidade circunvizinha do centro, implica abordarmos questões relacionadas com a mediação familiar. Esta mediação «deve ser vista como uma opção de amor e de respeito pelos adultos e pelas crianças envolvidas num processo de ruptura familiar e só preterida em benefício de outras abordagens, quando aquela se mostre absolutamente desadequada ao caso concreto» (QUINTANILHA 2011: 51).

De acordo com o tipo de instituição que nos propômos analisar e sendo a escola uma instituição na qual também se buscam contribuições para a inclusão social e para a formação do carácter dos indivíduos, outro tipo de mediação não menos importante para esta investigação é a mediação escolar. Neste âmbito, a mediação pode ser vista como um processo não formal, cuja resolução é fundamentada na espontaneidade das partes. Assim, pretende-se com este processo promover os valores como o respeito e o reconhecimento das partes (OLIVEIRA et al., 2011). Desse modo, podemos concluir que a mediação sociocultural parece-nos ser um potencial processo estimulador para a reabilitação e a reinserção social de indivíduos ou grupos de indivíduos.

Seguidamente, fazemos uma incursão sobre as estratégias e metodologias que se mostram apropriáveis tanto para a animação quanto para a mediação sociocultural (a dramatização, as dinâmicas de grupo; os métodos audiovisuais e os métodos não interferentes), não deixando de referir que estas devem ser utilizadas tendo sempre em conta os objectivos e particularidades de cada contexto. 


\section{A dramatização}

Católica. Passados longos anos, assiste-se ainda, actualmente, uma maior proliferação dos grupos teatrais sobretudo nas igrejas. Nesse contexto, é comum esses grupos pertencerem às igrejas ou, ainda, às instituições de ensino privadas. Existem no país um número reduzido de escolas onde se ensina o teatro. Estão na origem dessa situação, a carência de professores, a falta de incentivos a profissionalização, assim como a falta de políticas culturais e educacionais que promovam a prática da dramatização. Entretanto, constatamos que existem grupos de teatro independentes das instituições religiosas e/ ou escolares e muitos destes com recursos financeiros insuficientes. Por esse motivo, os grupos enfrentam diversas dificuldades como a fraca divulgação das actividades culturais, a falta de espaços culturais (no sentido de fazerem a apresentação dos seus trabalhos) e até mesmo a falta de condições de trabalho para prepararem a sua actividade. Neste contexto, pode-se concluir que a situação actual aponta para uma tímida expansão do teatro tanto ao nível do Estado como também ao nível das escolas e colégios privados.

31 profissionais do Centro, o teatro é uma das formas utilizadas para a reeducação dos 
menores internados. A dramatização aparece como uma metodologia utilizada pela totalidade dos nossos respondentes. Assim, esta metodologia é utilizada nas actividades produzidas em sala de aula e ainda nas actividades inerentes aos grupos de final de semana. As peças de teatro são apresentadas semanalmente e em ocasiões especiais. Normalmente, estas são exibidas no centro ou nas comunidades vizinhas. As peças têm como protagonistas os rapazes do centro e nelas são abordados temas da vida social dos menores. Nesse sentido, o objectivo da instituição é de trabalhar a inibição dos mesmos a fim de melhorarem a sua comunicação.

\section{As dinâmicas de grupo}

A expressão dinâmica de grupo é atribuída ao psicólogo alemão Kurt Lewin (DORTIER 2006). Lewin pretendia ensinar as pessoas a adquirirem os conhecimentos em grupos, constituindo cada elemento como agente participante da sua própria aprendizagem. A referida expressão foi criada com o objectivo de trazer inovações a pedagogia tradicional, que tinha como finalidade principal apenas a transmissão de conhecimentos. Nesse sentido, é esperado que esta «nova técnica» torne a aprendizagem mais interessante.

As dinâmicas de grupo são entendidas como as actividades feitas por várias pessoas com um objectivo comum. Contudo, através das actividades realizadas a partir dessas dinâmicas, é possível analisarmos diferentes níveis nos indivíduos: o nível de participação, o nível de interacção social e ainda o nível de aceitação das opiniões contrárias às suas. Outrossim, nessas actividades as dinâmicas de grupo são ferramentas através das quais os componentes do grupo expõem as suas ideias e após a discussão, a decisão final é tomada pelo grupo e não, apenas, por um dos seus elementos. Por esse motivo, pensamos que esta ferramenta de reciprocidade e de troca de experiências é um elemento condutor para o desenvolvimento de habilidades e competências dos indivíduos que dela fazem uso.

Existem várias classificações atribuídas às dinâmicas de grupo. Adoptamos nesta investigação a classificação apresentada por Celma Tavares e Nilsa Lira (2001), que as organiza em quatro diferentes tipos:

a. Dinâmicas de apresentação: esta técnica quebra as formalidades existentes no grupo;

b. Dinâmicas de descontracção: igualmente conhecidas como dinâmicas de recreação são, normalmente, utilizadas em situações de estagnação e nos momentos mais monótonos;

c. Dinâmicas de aplicação: denominadas por outros autores como dinâmicas de aprendizagem, são aquelas que simplificam o processo de aprendizagem através da repetição;

d. Dinâmicas de avaliação: com esta metodologia o grupo pode verificar até que ponto contribuiu para o progresso dos temas abordados.

Em suma, esta metodologia permite o desenvolvimento de um espírito de grupo e de equipa; dotado de fortes sentimentos de pertença, é um dos factores protectores essenciais na estratégia de "saber viver com os outros» numa estrutura residencial, inscrito no Manual de boas práticas do Grupo de Coordenação do Plano de Auditoria Social e do CID (2006). Assim, as dinâmicas de grupo potenciam a prolificação de fortes laços de amizade e de integração social e de uma maneira descontraída estimulam o espírito crítico. Já do ponto de vista lúdico, estas dinâmicas aportam um resultado duradouro da aprendizagem. 

observar que aí é comum a utilização desta metodologia. A totalidade dos nossos respondentes afirma fazer o uso da mesma nas suas actividades com os alunos. Este facto pressupõe que as dinâmicas de grupo estão entre as metodologias de maior adesão nesse centro de formação profissional. De acordo com os educadores, esta metodologia efectuada em grandes ou em pequenos grupos realiza-se durante as aulas e ainda durante os finais de semana. Para além de visar uma maior coesão entre os alunos internados, o seu aspecto lúdico torna-se numa ferramenta útil para o processo de reeducação.

Desse modo, as dinâmicas de grupo são aplicadas durante as três actividades diárias denominadas «Bom-dia», «Boa-tarde» e «Boa-noite». Estas actividades, que promovem diariamente mensagens que enaltecem os valores essenciais da pessoa humana, constituem os momentos de avaliação e de reflexão das acções desenvolvidas durante o dia.

Por outro lado, essas dinâmicas são, ainda, empregadas numa outra actividade denominada «Passeio dos campeões». Participa desta actividade apenas os internados que tenham tido um bom comportamento durante um certo período de observação. No entanto, este tipo de actividade torna-se cada vez menos frequente devido a dificuldades financeiras que o centro enfrenta. Em todo caso, foram também mencionados alguns obstáculos na aplicação dessa metodologia como a carência de material.

\section{Os métodos audiovisuais: a fotografia e o vídeo}

Em investigação social, estes dois métodos visuais podem revelar situações não referenciadas pelos interlocutores durante o momento das entrevistas. A fotografia e o vídeo permitem a captação/«congelamento» das imagens e dos momentos que podem ser revividos em outras épocas e/ou por outros indivíduos. Trata-se de duas fontes de comunicação visual. Quer com isso dizer, que tanto um método quanto o outro é potencialmente capaz de transmitir informações através do uso da visão, facto que podemos confirmar no pensamento de João Teixeira Lopes, segundo o qual

\footnotetext{
«a fotografia enquanto técnica de investigação empírica, distinta, por conseguinte, quer dos seus usos propriamente estéticos e/ou artísticos, quer dos seus usos familiares, quer, ainda, dos usos especificamente arquivísticos e documentais, funciona como uma excelente fonte de informação visual concreta sobre a pertinência e validade de conceitos e modelos teóricos, intrinsecamente abstractos» (LOPES 2007: 12).
}

Nesse sentido, uma imagem desperta várias interpretações possíveis dependendo das perspectivas de quem a observa; daí se atribuir um carácter multifacetado a fotografia. O conteúdo da fotografia encontra-se na interpretação e nos mais diversos significados que se dão à mesma. Deste modo, a fotografia deve ser interpretada e a forma de interpretá-la deve ir de encontro aos objectivos da pesquisa. Contudo, notamos que os comportamentos podem mudar perante as câmaras de vídeo ou fotográficas. Nesta senda, estes meios visuais podem não transmitir a situação real do contexto de estudo, pois «as pessoas que não sabem que estão a ser estudadas não modificam o seu comportamento» (LEE 2003: 92). 
41 Por seu turno, em alguns momentos da investigação, a utilização do vídeo pode se mostrar crucial para a colheita de dados, sobretudo porque esta técnica regista os momentos, apresentando detalhes que podem escapar numa simples observação visual, sem contar que as imagens permanecem gravadas durante longos períodos de tempo, permitindo ao investigador a sua consulta sempre que necessite. Todavia, os métodos visuais devem ser complementados com outros métodos de investigação.

Gráfico n..$^{\circ} 1$ - Distribuição da amostra relativa ao recurso aos meios audiovisuais

\section{Recurso aos meios audiovisuais}

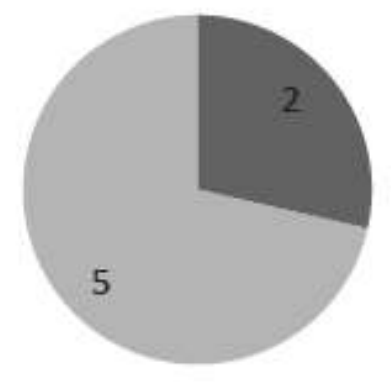

Recorre aos meios

Não recorre aos meios

Fonte: AUTORA com fotografias.

Relativamente a utilização dos meios audiovisuais em Kalakala, consta no Gráfico n. 1 que nem todos os educadores recorrem a esses meios. Como constatado na caracterização socioprofissional dos funcionários de Kalakala, os profissionais do Centro apresentam um défice em termos de formação académica, facto que dificulta de certa forma o bom funcionamento do seu trabalho. Conforme as ideias de um dos funcionários, esta situação reflecte na fraca utilização dos meios audiovisuais nas actividades em sala de aulas. Entretanto, esses meios são sobretudo utilizados durante as actividades extra escolares e nas actividades de final de semana.

Deste modo, nas actividades de final de semana, o Centro oferece aos internados algumas sessões de filmes denominadas «Cine-aldeias». Tais sessões visam criar ocasiões de relaxamento e aprendizagem através da visualização de filmes. Assim, os menores têm a possibilidade de se juntarem em comunidade, proporcionando momentos de confraternização e integração social. As sessões de vídeo são seguidas de discussões, permitindo, assim, que os internados possam dar a sua opinião sobre os temas abordados. Neste sentido, essas sessões servem, também, de motivadores para a comunicação e respeito das ideias de outrem. Ainda nesta perspectiva, um outro instrumento, também utilizado como meio visual, é o jornal de parede. Como todo jornal, para além das notícias referentes às actividades do centro, também, é ilustrado

4 Por outro lado, são ainda empregados como meios visuais, para além da fotografia, os cartazes utilizados nas aulas de alfabetização dos menores. De maneira conclusiva, os métodos visuais são instrumentos de análise social. Uma das suas vantagens é que tais instrumentos permitem a passagem de informações que nem sempre é possível transmiti-las de forma verbal. 


\section{Os recursos não interferentes}

Os recursos não interferentes em pesquisa social servem para a recolha de informações, sem que os indivíduos estudados se apercebam da situação. Isto pode acontecer para impedir que estes tragam «contaminações» a pesquisa. Nesta recolha, quando feita por outros meios de colheita de dados como o caso das entrevistas, o investigador pode correr o risco de recolher dados que na sua totalidade podem não ir de encontro com a situação real dos factos. Por outro lado, dadas as características que este método apresenta, assim como, também, as particularidades próprias do investigador, as entrevistas podem causar algum desconforto aos indivíduos entrevistados, levando-os, por vezes, a fornecer as informações mais convenientes para si.

Neste sentido, fazer pesquisas sem que o público-alvo ou o objecto da investigação se sinta observado, pode transformar-se em um «elemento de pesquisa natural» muito proveitoso. No que diz respeito a disponibilidade dos entrevistados, por exemplo, o investigador que utiliza métodos não interferentes, não deve estar preocupado com este aspecto e, muito menos, com o facto de alguns entrevistados não colaborarem em responder as questões colocadas durante as entrevistas.

Ainda neste prisma, um elemento que favorece a investigação com os recursos não interferentes é a discrição do investigador, uma vez que os sujeitos investigados não notam a sua presença. As práticas, os modos e as conviç̧ões de uma sociedade podem ser estudadas, fazendo-se o uso de métodos não interferentes como a observação indirecta e as fontes documentais. Desse modo, os resultados da investigação podem ser os mesmos em relação aos resultados obtidos em uma investigação em que se utilizam os métodos aparentemente mais participativos para o investigador como é o caso da observação participante, das entrevistas e dos questionários (Webb et al., 1966 cit. por LEE 2003).

48 Assim sendo, a observação é portanto uma maneira de identificar a forma como programamos e distribuímos a nossa vida. Ter noção de pequenas coisas, que inúmeras vezes podem passar despercebidas, como a noção e a utilidade que damos ao tempo e ao espaço, mostram-se como elementos passíveis da utilização da observação simples como método não interferente de pesquisa social.

Relativamente às técnicas de registo com métodos não interferentes, distingue-se a utilização da fotografia e do vídeo. Desta forma, a fotografia pode auxiliar a análise dos dados recolhidos durante a fase das entrevistas. Tendo em conta que os sujeitos a serem fotografados não se apercebam da investigação, a utilização da fotografia como método não interferente pode refutar a ideia de que é necessário fazer pose para ser fotografado, realçando assim o que anteriormente chamamos de elemento de pesquisa natural.

50 Contudo, apesar de terem sido anteriormente apresentados alguns aspectos positivos da investigação feita com o auxílio dos recursos não interferentes, é salutar que os indivíduos sujeitos a uma pesquisa possam tomar conhecimento da mesma. Porém, se o investigador não interferir e não colocar em risco a integridade e privacidade dos referidos indivíduos, não nos parece desmedido realizar uma investigação sem o consentimento dos investigados. 


\section{Recurso aos métodos não interferentes}

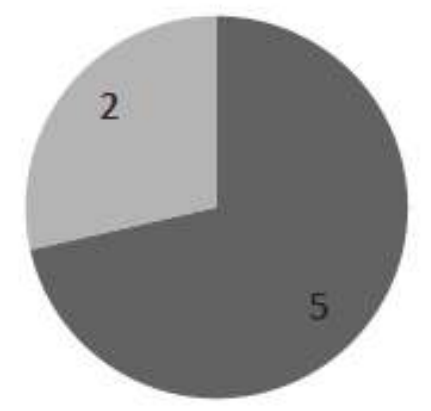

Recorre aos métodos

Não recorre aos métodos

Fonte: AUTORA

51 Quanto a utilização dos métodos não interferentes no centro de formação Kalakala, ao atentarmos a leitura do Gráfico n.․ㄹ 2, notamos que a aderência a estes métodos não é total. Contudo, esta aderência é feita em duas perspectivas:

1. Os educadores utilizam os métodos não interferentes fora da sala de aula, recorrendo à observação dos alunos, no espaço físico comum da instituição. Está aqui patente a questão da presença frequente e obrigatória dos educadores nesses espaços. De acordo com o método preventivo, onde há um internado deve haver sempre um educador, isto é, os alunos devem estar em contacto constante com os educadores.

2. Dentro da sala de aula, para além da observação, os educadores apelam para a avaliação contínua feita aos alunos sem o conhecimento dos mesmos.

\section{Discussão: Conclusões}

Com essa investigação, procuramos compreender todo o processo de reeducação e reintegração social dos menores internados no Centro de Formação Kalakala, nomeadamente, as implicações e as transformações vividas por esses indivíduos. Nesse sentido, para respondermos as questões que nos propusemos no início, ao analisarmos a situação social dos internados, constatamos que os menores de Kalakala têm características muito semelhantes, visto que, nas suas linhas de homogeneidade, esses indivíduos têm uma condição social idêntica. Assim, encontramos, sobretudo, indivíduos adolescentes e jovens oriundos de famílias pobres, moradores de bairros sociais com difícil acesso a educação, com histórico de vivência na rua e com algum histórico de consumo de drogas.

Relativamente ao processo de reeducação e reintegração social na instituição, este ocorre de forma simultaneamente individual e social. Nesse sentido, independentemente das estratégias adoptadas no centro para a reabilitação dos menores, um dos principais elementos na reeducação e reinserção social dos mesmos é a vontade que esses indivíduos demonstram em passar por esse processo. Porém, essa mesma reinserção social depende também, por outro lado, da aceitação dos menores por parte da sociedade, especialmente por parte das suas famílias. Porquanto, este processo visa harmonizar relações entre indivíduos que experimentam a exclusão 
social e a marginalização a diversos níveis, dando-lhes uma nova oportunidade de boa convivência social.

Nessa óptica, segundo as ideias dos educadores de Kalakala, o processo de reeducação e reintegração social oferecido pela instituição, proporciona aos seus usuários uma nova visão da vida, incentivando-os a tornarem-se indivíduos preparados para a vida e capazes de adoptar uma postura social digna. Desta forma, aos novos aprendizados permite-se ganhar o gosto pela escola, aprender diversas profissões e ainda tornaremse pessoas melhores, o que beneficia a si e também às suas redes sociais.

Assim, um aspecto vantajoso no processo de reintegração social dos adolescentes e jovens que passam por Kalakala, é o apoio prestado pela instituição no momento da integração dos ex-alunos no mercado de trabalho. Ao longo do período de formação, são realizadas visitas pedagógicas a determinadas empresas com o objectivo de promover a interacção dos jovens, com pessoas em pleno exercício de funções, para conhecimento de certas rotinas de trabalho. Nessa perspectiva, a instituição tem acordos pontuais com a administração local e com outras instituições estatais, com a finalidade de encontrar o primeiro emprego para esses jovens no final da sua formação; isto ocorre, sobretudo, quando as famílias não os podem acolher, ou quando estes não conseguem emprego por outras vias. Ainda acerca dos resultados obtidos de todo o processo de reintegração social dos menores, até ao momento da presente investigação, a instituição fez sair para o mercado de trabalho trinta e dois alunos que terminaram o curso no ano de 2011. Efectivamente, vinte desses indivíduos foram reinseridos nas suas famílias ao passo que os doze restantes vivem actualmente em uma casa autónoma pertencente aos Salesianos e já estão inseridos no mercado de trabalho. De acordo com a visão dos menores, podemos constatar o elevado valor social que estes indivíduos atribuem a instituição em relação a sua reeducação e reinserção social.

De modo geral, verificamos que o processo de reeducação e reintegração dos menores com recurso as estratégias e metodologias da animação e da mediação sociocultural, é feito, em grande medida, nas actividades extra escolares ou actividades de final de semana dentro do Movimento Juvenil Salesiano.

Relativamente a qualificação dos profissionais do centro, de acordo com os documentos da instituição, um dos desafios que o centro enfrenta está relacionado com a procura de profissionais qualificados, aptos para acompanhar de maneira pedagógica a reentrada dos jovens na sociedade e a respectiva entrada no mundo do trabalho. Contudo, é necessário considerar que

«os recursos humanos constituem um elemento fundamental para o sucesso ou insucesso de qualquer organização [...]. A qualidade dos cuidados prestados está intimamente ligada à qualidade humana daqueles que os prestam. Assim, para além das capacidades técnicas e académicas, devem ser igualmente valorizadas e atendidas características pessoais como a sensibilidade, afectividade, idoneidade, abertura e disponibilidade para interagir com o outro» (GRUPO DE COORDENAÇÃO DO PLANO DE AUDITORIA SOCIAL e CID 2006: 140).

Deste modo, verificamos que o quadro de profissionais de Kalakala não está provido de profissionais da animação e nem da mediação sociocultural. Encontramos, porém, profissionais ligados a outras áreas sociais como a área da educação social (não obstante o facto de um animador poder ser chamado educador social, cf. LARRAZÁBAL 2004), a área da assistência social, a área da pedagogia e ainda a área da economia. 
59 Assim, podemos concluir que apesar de os educadores do centro de formação Kalakala fazerem recurso à dramatização, as dinâmicas de grupo, aos métodos audiovisuais e aos métodos não interferentes, os mesmos não reconhecem estas práticas educativas como metodologias da animação sociocultural, ou seja, essas metodologias não são utilizadas de forma consciente como metodologias da animação sociocultural, mas sim, são utilizadas apenas como meras estratégias e técnicas para a reabilitação dos internados.

Por outro lado, como estratégias e metodologias da mediação sociocultural, estas são utilizadas de forma mais consciente, sendo que a mediação aparece como um promotor da resolução de conflitos. 0 trabalho efectuado pelos educadores do centro permite fazer a mediação de conflitos entre os internados; a mediação de conflitos entre os internados e os educadores, e também, a mediação de conflitos entre os internados e os seus familiares. Desse modo, uma vez que é de grande importância, não apenas a reinserção social, mas sobretudo, a reinserção familiar desses indivíduos, apesar do fraco envolvimento das famílias no processo de reintegração familiar (após a sua saída do centro), esta reintegração é feita com base no processo de mediação entre a instituição e as famílias respectivamente.

61 Constatando os resultados desta investigação, pensamos que incentivar a aplicação de estratégias e metodologias da animação e da mediação sociocultural, na reeducação e reintegração social dos menores é uma mais-valia para os indivíduos implicados nesse processo. Assim, foi também possível compreendermos o significado que esses indivíduos atribuem às actividades realizadas no centro de formação. Desta forma, verificamos que os internados consideram essas actividades como condutoras de alterações ao nível dos auto conceitos, ao nível dos valores pessoais, e também, ao nível das práticas sociais. No mesmo sentido e na perspectiva dos profissionais em relação ao processo de reabilitação dos menores internados no Centro de Formação Integral Kalakala, é unânime a ideia segundo a qual os resultados obtidos através das actividades realizadas são muito satisfatórios, isto é, os objectivos traçados pelo centro foram alcançados.

62 Entretanto, do que nos foi dado a observar, é de lamentar o facto de se fazer pouca exploração das metodologias da animação e da mediação sociocultural nos currículos escolares angolanos; acreditamos que a sua utilização facilitaria e muito poderia contribuir para o desenvolvimento dos alunos no que diz respeito a espontaneidade, a comunicação, a tomada de iniciativas, entre outros. Porém, esta investigação permitiunos também perceber que o não reconhecimento dessas práticas, como metodologias da animação e da mediação sociocultural por parte dos educadores de Kalakala, não impediu que a aplicação dessas estratégias e técnicas fosse eficaz para a reeducação e reintegração social de indivíduos menores que vivem em situação de risco.

Uma vez alcançados os nossos objectivos e respondidas as questões que nortearam esta investigação, passamos de seguida a uma breve abordagem sobre os desafios e as limitações da mesma. Primeiramente, apresentamos como desafio o acesso ao Centro de Formação Integral Kalakala, devido a sua localização geográfica, pois o centro encontra-se situado na periferia da cidade de Luanda.

Temos também a destacar a insegurança dos entrevistados em participarem deste processo. No entanto, Quivy e Campenhoudt justificam esta atitude ao afirmarem que isto tem que ver com «o receio de servirem de cobaias e o de verem as suas próprias condutas avaliadas [...]» (QUIVY e CAMPENHOUDT 1992: 82-83). Apesar desta observação, consideramos essa insegurança uma dificuldade. Lamentamos, de igual modo, a 
restrição concernente a duração do estudo que não nos permitiu fazer uma observação participante para melhor apreciação do processo de reeducação e de reabilitação aplicado no Centro de Formação Integral Kalakala. Porém, foi possível entendermos, de forma muito tímida, alguns elos existentes entre os diferentes membros participantes de todo esse processo (o colectivo de alunos internos; os internos e a comunidade; os internos e as suas famílias e, ainda, entre os educadores e as famílias dos internos).

Nessa óptica, seria igualmente de nosso interesse explorar dois aspectos: primeiramente, acompanharmos os resultados obtidos através do processo de mediação no desenvolvimento da relação menor/família (uma vez que parte dos indivíduos que compõem a nossa população alvo são sujeitos provenientes das ruas e com alguma dificuldade de serem localizadas as respectivas famílias, não poderíamos avaliar os efeitos do poder familiar e nem a reinserção familiar desses indivíduos). Seguidamente, verificarmos em que medida os ex-alunos do Kalakala são reincidentes ou não, em relação à vida que tinham antes da sua entrada na instituição.

Além disso, seria útil também conhecermos quais são as funções e que posição ocupa um animador e um mediador sociocultural na sociedade angolana. Todavia, pensamos que é necessário ampliar o número de profissionais nessas áreas e melhorar o nível de intervenção dos mesmos, nas práticas educativas em Angola.

67 Contudo, esperamos que esta investigação sirva para impulsionar uma visão mais abrangente daquilo que são as estratégias e metodologias da animação e da mediação sociocultural. Esperamos ainda que a mesma sirva, por um lado, para incentivar o uso dessas estratégias e técnicas ao nível de outras instituições em Angola e que, por outro lado, sirva de suporte para investigações futuras.

\section{BIBLIOGRAFIA}

BOURDIEU Pierre (dir.), 2003, A miséria do mundo. Petrópolis, Editora Vozes.

CRESWELL John W., 2007 (2. edição), Projecto de pesquisa: Métodos qualitativo, quantitativo e misto. Tradução de Luciana de Oliveira da Rocha. Porto Alegre, Artmed.

DORTIER Jean-François (coord.), 2006, Dicionário das Ciências Humanas. Prefácio de Jean-François Dortier. Tradução de Maria do Rosário Paiva Boléo. Lisboa, CLIMEPSI Editores.

GRUPO DE COORDENAÇÃO DO PLANO DE AUDITORIA SOCIAL e CID, 2006, Manual de boas práticas: um guia para o acolhimento residencial das crianças e jovens. Lisboa, Instituto da Segurança Social, I.P.

LARRAZÁBAL Maria S., 2004, «A figura e a formação do animador sociocultural», in J. Trilla (coord.) Animação sociocultural. Teorias, programas e âmbitos, Lisboa, Instituto Piaget [«Horizontes Pedagógicos»], pp. 123-134.

LEE Raymond M., 2003, Métodos não interferentes em pesquisa social. Tradução de Eduardo de Freitas. Lisboa, Gradiva [«Trajectos»; 55].

LESSARD-HÉBERT Michelle et al., 1994, Investigação qualitativa: Fundamentos e práticas. Tradução de Maria João Reis. Lisboa, Instituto Piaget [«Epistemologia e Sociedade»; 21]. 
LOPES João Teixeira, 2007, Da democratização à democracia cultural. Uma reflexão sobre políticas culturais e espaço público. Porto, Profedições.

LOPES João Teixeira e AIBÉO Bárbara, 2007, Os públicos da cultura em Santa Maria da Feira. Relatório de síntese. Porto, Edições Afrontamento.

OLIVEIRA Ana e GALEGO Carla (com a colaboração de Laura Gouveia), 2005, A mediação sóciocultural: Um puzzle em construção. Lisboa, ACIME [«Observatório da imigração»; 14].

OLIVEIRA Isabel; LEITE Miguel; PESSOA Sílvia, 2011, «Mediação escolar: Desenho e implementação do Projecto - o 1.․ Ano», in Pedro Cunha (coord.), Actas do II Colóquio sobre mediação. Reflexões práticas, realizado na Universidade Fernando Pessoa (Porto), em 16 de Abril de 2008. Porto, Edições da Universidade Fernando Pessoa.

QUINTANILHA Anabela, 2011, «Mediação familiar. Entre a teoria e a prática os casos reais», in Pedro Cunha (coord.), Actas do II Colóquio sobre mediação. Reflexões práticas, realizado na Universidade Fernando Pessoa (Porto), em 16 de Abril de 2008. Porto, Edições da Universidade Fernando Pessoa.

QUIVY Raymond e CAMPENHOUDT Luc Van, 2003 (3. edição), Manual de investigação em Ciências Sociais. Tradução de João Minhoto, Maria Amália Mendes e Maria Carvalho. Lisboa, Gradiva [«Trajectos»; 17].

SANTOS Maria de Lourdes Lima dos (coord.), et al., 1998, As políticas culturais em Portugal: Relatório nacional. Lisboa, Observatório das Actividades Culturais.

SOUSA Maria da Conceição Figueira de, 2004, «Animação sociocultural, conflito social e marginalização», in Animação sociocultural. Teorias, programas e âmbitos. Lisboa, Instituto Piaget [«Horizontes pedagógicos»].

SOUSA Maria José de e BAPTISTA Cristina Sales, 2011, Como fazer investigação, dissertações, teses e relatórios - segundo Bolonha. Lisboa, Pactor.

TAVARES Celma e LIRA Nilsa (orgs.), 2001, Construindo uma cultura de paz. Oficinas pedagógicas. Recife, Movimento Tortura Nunca Mais.

TRILLA Jaume (coord.), 2004, Animação sociocultural. Teorias, programas e âmbitos. Tradução de Ana Rabaça. Lisboa, Instituto Piaget [«Horizontes Pedagógicos»; 115].

VASCONCELOS-SOUSA José, 2011, «A mediação nas empresas: Oportunidades de redução de custos», in Pedro Cunha (coord.), Actas do II Colóquio sobre mediação. Reflexões práticas, realizado na Universidade Fernando Pessoa (Porto), em 16 de Abril de 2008. Porto, Edições da Universidade Fernando Pessoa.

\section{RESUMOS}

Esta investigação visa comprovar a necessidade de empregar técnicas educativas eficazes no programa de reeducação e reinserção social de menores em risco. Assim, o objectivo principal é de apresentar a utilização e eficácia das metodologias da animação e mediação sociocultural (dramatização, dinâmicas de grupo, métodos audiovisuais e métodos não interferentes) no programa de reinserção social do Centro de Formação Integral Kalakala. Nesse sentido, recorremos para esse estudo de caso a metodologia qualitativa apoiada em: entrevistas semidirectas com questões abertas; observação directa do tipo exploratória; análise documental baseada em fontes oficiais em Angola e pesquisa bibliográfica. Como principais resultados, constatamos que os educadores de Kalakala recorrem às metodologias, mas não as reconhecem 
como metodologias da animação sociocultural; o recurso dessas metodologias é feito nas actividades extra-escolares; as metodologias da mediação sociocultural são utilizadas de forma mais consciente; a aplicação dessas metodologias é eficaz para a reeducação e reintegração social dos jovens.

The objectives of this scientific investigation studies, is to prove the needs of the implementation of efficient academics techniques into the re educational and social reintegration program for the Minors at risk. Therefore, the main objective is to present the use and efficiency of the sociocultural animation and mediation methods (dramatization group dynamics, audiovisual methods and non interference methods) on the Centro de Formação Integral Kalakala Social Reintegration Program. We have then choosed for this particular Study the qualitative methodology based upon open questions semi-directive interview, direct explorative observation, documental analysis based on official/ authorized sources in Angola and bibliographic investigation. The results has shown us the following: the Lecturers at Kalakala's Centre makes full use of these methodologies but they do not recognize it as a sociocultural animation methods; this method is implemented during the extracurricular activities; the sociocultural mediation methodology is used with more awareness; the application of these methodologies is efficient for the reeducation and social reintegration of the Minors.

\section{ÍNDICE}

Keywords: social and cultural animation, mediation, reeducation, social rehabilitation

Palavras-chave: animação sociocultural, mediação, reeducação, reintegração social

\section{AUTOR}

\section{TEODORA LEITE}

teodora.leite@yahoo.com

Assistente da Faculdade de Economia (FE) da Universidade Agostinho Neto (UAN).

É Mestre em Sociologia pela Faculdade de Letras da Universidade do Porto (Portugal) e Licenciada em Ciências da Educação pelo Instituto Superior de Ciências da Educação (ISCED) de Luanda. É docente da Faculdade de Economia (FE) da Universidade Agostinho Neto (UAN), onde lecciona as disciplinas de Sociologia, Psicossociologia das Organizações e Metodologia de Investigação Científica (MIC). Integra o Conselho Editorial da Revista da Faculdade de Economia da UAN. 